\title{
Effect of Chronic Treatment with Clomipramine on Food Intake, Macronutrient Selection and Body Weight Gain in Rats
}

\author{
Leonardo Calegari,${ }^{a, d}$ Clarice Gorenstein, ${ }^{b}$ Valentim Gentil,${ }^{c}$ Cleopatra Silva Planeta, ${ }^{a}$ and \\ Ricardo Luiz NunES-DE-SouZA*,a \\ ${ }^{a}$ Laboratory of Pharmacology, School of Pharmaceutical Sciences, São Paulo State University; 14801-902 Araraquara, \\ SP, Brazil: ${ }^{b}$ Laboratory of Neuropsychopharmacology, Institute of Biomedical Sciences, University of São Paulo; \\ 05508-900, São Paulo, SP, Brazil: ' Department and Institute of Psychiatry, University of São Paulo Medical Center; \\ 01060-970 São Paulo, SP, Brazil: and 'Programa de Pós-Graduação em Ciências Fisiológicas, UFSCar/Convênio \\ UNESP. Received April 28, 2007; accepted May 30, 2007
}

\begin{abstract}
Long-term treatment with clomipramine (CMI), a tricyclic antidepressant, induces food craving and body weight gain in patients. The present study investigated the effects of chronic treatment with CMI on total food intake, macronutrient selection, and body weight gain in rats. Male Wistar rats were maintained on a dietary selfselection regime with separate sources of protein, fat and carbohydrate. Animals received i.p. injections of CMI $(0,3,10,30 \mathrm{mg} / \mathrm{kg})$ during 27 consecutive days. Food consumption and body weight were recorded daily and results were calculated as average of three consecutive days, namely during pre-treatment ( $3 \mathrm{~d}$ before pharmacological treatment), treatment (7th-9th; 16th-18th and 25th-27th days), and post-treatment (28th-33rd days). Results showed that CMI $(30 \mathrm{mg} / \mathrm{kg})$ significantly decreased energy intake during all treatment period, an effect that was related to a decrease in both carbohydrate-rich diet intake and body weight gain. At dose of $3 \mathrm{mg} / \mathrm{kg}$ CMI increased the total energy intake in the 16th-18th days, suggesting an apparent biphasic effect of chronic treatment with CMI on caloric intake. Chronic administration with CMI (27 d) did not alter protein-rich or fatrich diet consumption. The main result of this study indicated that chronic treatment with CMI decreases rather than increase food consumption and body weight gain in rats exposed to a macronutrient self-selection procedure.
\end{abstract}

Key words macronutrient self-selection; chronic treatment; clomipramine; carbohydrate; fat; protein; rat

Weight gain is a frequent side effect observed during drug treatment of psychiatric disorders. ${ }^{1)}$ It often contributes towards patient non-compliance and discontinuation of the pharmacological treatment. ${ }^{2)}$ Weight gain may also contribute to comorbidities such as hypertension, coronary heart disease, diabetes, and stroke. ${ }^{3,4)}$ Weight gain is also a relatively common problem during both acute and long-term treatment with antidepressants. It appears that tricyclic antidepressants (TCA) may be more likely to cause weight gain as compared to selective serotonin reuptake inhibitors (SSRIs), a class of antidepressant widely used in clinical practice ${ }^{5,6)}$ Among them amitriptiline, doxepin, imipramine, trimipramine, maprotiline, nortriptyline, and clomipramine are reported to cause marked weight gain. ${ }^{2)}$

TCA may affect appetite by blocking the reuptake of serotonin and noradrenaline. Serotonin is recognized to have an influence on food intake and macronutrient selection. ${ }^{7,8)}$ Noradrenaline has also been shown to have an effect on food intake that opposes the effects of serotonin, but its effects on macronutrient selection are not clear. ${ }^{7,9,10)}$ TCA may also affect appetite by blocking histaminergic (H1) pathways. ${ }^{11)}$ However, the mechanisms underlying the weight gain induced by antidepressants treatment have yet to be understood. In clinical studies, it has been found that antidepressant drugs alter nutrient selection, inducing in particular a preference for high-carbohydrate or sweet foods. ${ }^{12-14)}$ Early efforts to model these effects in rats have led to contradictory results. For example, it has been shown that acute systemic injections of clomipramine selectively enhance carbohydrate intake. ${ }^{15)}$ On the other hand, it has been reported that food intake was initially and significantly decreased by desmethylimipramine treatment but this effect progressively returned towards pretreatment levels over the course of the drug administration $(30 \mathrm{~d}) .{ }^{16)}$ Such discrepancies may be related to brain monoamine receptor neuroadaptations following chronic treatment with antidepressants. ${ }^{17-21)}$ Nobrega and Coscina $^{22)}$ evaluated the effects of the chronic treatment with two other TCA, amitriptyline and desipramine on food selection. They showed that desipramine decreased food intake and body weight, while amitriptiline did not change food intake and body weight or slightly reduced them in comparison to vehicle-treated controls. However, strict macronutrient protocols (using separate sources of pure macronutrients) have rarely been tested in rats following the chronic treatment with TCA. Therefore, it remains unclear whether this class of antidepressants change macronutrient selection and weight gain in rats. Given that and there is only limited evidence on the effects of TCA on macronutrient selection especially over long periods of drug treatment, the present study was carried out to explore the effects of chronic treatment with clomipramine (CMI) on food intake, macronutrient selection and body weight in male rats allowed to self-select among macronutrients. The development of animal models is crucial to investigate the underlying neural mechanisms involved the weight gain produced by antidepressants drugs. Clomipramine was chosen for the present study due to the following reasons: (i) it has high potential to induce weight gain $^{2)}$; (ii) it is a reference drug for treatment of emotional disorders such as obsessive-compulsive disorder and panic disorder $^{23)}$ and (iii) it has been widely used for treatment of psychiatric disorders as well as in clinical researches in Brazil $^{24-28)}$ and recent evidence from our research group has indicated that $\mathrm{CMI}$ induces weight gain in healthy volunteers (results not published). 


\section{MATERIALS AND METHODS}

Animals and Diets Twenty-eight male adult Wistar rats weighing $230-250 \mathrm{~g}$ were used. Animals were housed in individual cages under controlled temperature $\left(22 \pm 1^{\circ} \mathrm{C}\right)$ and constant 12:12-h light/dark cycle with lights on at 7:00 a.m.

The experimental procedures carried out in this study comply with the norms of the Brazilian Neuroscience and Behavior Society ( $\mathrm{SBNeC}$ ) that is in accordance to US National Institutes of Health Guide for Care and Use of Laboratory Animals.

A Diet Scan data acquisition system $\left(\right.$ Insight $^{\mathbb{Q}}$, Brazil) connected to a PC was used to record food consumption. The system consisted of five individual acrylic cages $(40 \times 40 \times$ $40 \mathrm{~cm}$ ) equipped with electronic balances for each macronutrient-rich diet (see diets composition in Table 1). A food tray was placed on each balance and filled with a macronutrientrich diet. Rats had access to the food through 3 circular sets of 5 holes $(3.5 \mathrm{~cm}$ diameter) on the cage's floor, and to water through a drinking bottle. Each circular set has an edge of $1.0 \mathrm{~cm}$ height to prevent that animals spill food out the circular sets. The macronutrient's trays were replaced daily with fresh food and placed in the experimental cage in a different position to avoid any place preference. To ensure minimal disturbance to the animals during the active dark period, delivery of fresh food, body weight measurements, cleaning of cages, and resetting the Diet Scan system were scheduled daily between 10:00 a.m. and 11:00 a.m. Food intake was measured in 30-min intervals across $23 \mathrm{~h}$ (starting at 11:00 a.m.) and the data were automatically recorded by the Diet Scan data acquisition system.

Rats were randomly divided into four groups; Saline $(n=7) ; \mathrm{CMI} 3 \mathrm{mg} / \mathrm{kg}(n=8), \mathrm{CMI} 10 \mathrm{mg} / \mathrm{kg}(n=7)$, and CMI $30 \mathrm{mg} / \mathrm{kg}(n=6)$. Animals were provided ad lib with water and the three macronutrient-rich diets. Protein-rich diets were offered in a granular form, which were prepared by adding a fixed amount of water to powdered casein $(50 \mathrm{ml}$ water to $100 \mathrm{~g}$ protein diet). The mixture was then stirred to obtain a granular consistency. Granular diets were left to dry overnight. Weights of granular diet were checked in the following day to ensure that granular diet weights were similar to the weight of the powder diets before the addition of water. ${ }^{29)}$ Carbohydrate and fat diets were offered respectively in a powder and paste form.

Experimental Design and Treatment Animals were transferred to the laboratory and allowed a 5-d period to adapt to the laboratory conditions and diets. Animals that had failed to gain weight during this period were excluded from the study. The experimental procedure consisted of three phases: a) pre-treatment: macronutrient intakes were recorded during three consecutive days before the beginning of drug treatment; b) treatment: on the fourth day, the drug treatment started. Animals received i.p. injections of saline or CMI (3-chloro-10,11-dihydro- $N, N$-dimethyl-5H-dibenz[b,f]azepine-5-propanamine hydrochloride, Tocris, U.K.), (3, 10 or $30 \mathrm{mg} / \mathrm{kg}$ ) during 27 consecutive days. Food intake was recorded daily for three consecutive days, namely 7 th -9 th; 16 th -18 th and 25 th -27 th days. In the other days, animals were individually housed in their home-cages and were fed with commercial nonpurified stock diet (Purina Rat Laboratory Chow); c) Post-treatment: from 28th to 33rd days, ani-
Table 1. Composition of Macronutrient Diets (Dry Weights, \%, g/100 g)

\begin{tabular}{lccc}
\hline \hline \multicolumn{1}{c}{ Ingredients $^{a)}$} & Carbohydrate & Protein & Fat \\
\hline Casein, high nitrogen & - & 92.6 & - \\
Corn starch & 62.8 & - & - \\
Powdered sugar & 30 & - & - \\
DL-Methionine & - & 0.19 & - \\
Vegetable shortening & - & - & 92.8 \\
AIN-76 vitamin mix & 1 & 1 & 1 \\
AIN-76 mineral mix & 4 & 4 & 4 \\
Choline chloride & 0.2 & 0.2 & 0.2 \\
Cellulose & 2 & 2 & 2 \\
Energy density (kcal/g diet) & 3.70 & 3.70 & 8.40 \\
\hline
\end{tabular}

a) Rhoster-Industry and Trade-SP-Brazil. b) The vitamin and mineral mixes contain $97 \%$ and $12 \%$ sucrose, respectively.

mals were kept in their home-cages with the same commercial diets described above. On the 34th day they were transferred to experimental cages and food intake was recorded daily for $3 \mathrm{~d}$ (34th-36th). The whole experiment lasted $44 \mathrm{~d}$. Results were expressed as average of food intake for each block of $3 \mathrm{~d}$ [i.e. pretreatment (1 block); treatment ( 3 blocks) and post-treatment (1 block)]. CMI solution was kept frozen and fresh solutions were prepared and injected intraperitoneously daily at 17:00.

Statistical Analysis Macronutrient intakes were converted to kilocalories and expressed as mean \pm S.E.M. All results (body weight and food intake) were initially submitted to Levene's test for homogeneity of variance. When appropriate, the data were $\log$ transformed and then analyzed by ANOVA (as described below). When Levene revealed statistical significance for the log-transformed data, data were analyzed by Kruskal-Wallis test followed by Dunn's test. Macronutrient intakes were analyzed by a $4 \times 5$ analysis of variance (ANOVA) for repeated measures (i.e., drug treatment (CMI 0, 3.0, 10, 30 mg/kg) as independent factor and blocks of food measurements (pretreatment (1 block), treatment (3 blocks) and post treatment (1 block)) as dependent. When a significant main effect was detected, the $F$ test for contrasts between pair of means was used for post hoc comparisons. In all cases, a $p$ value $\leq 0.05$ was considered significant.

\section{RESULTS}

Body Weight Figure 1 shows body weight gain throughout the experiment. ANOVA revealed a significant main effect of treatment $[F(3,24)=7.05, p=0.001]$ and period $[F(4,96)=563.6, p<0.001]$ and also a significant treatment $\times$ period interaction $[F(12,96)=10.0, p<0.001]$. Body weight was significantly lower in animals treated with $30 \mathrm{mg} / \mathrm{kg}$ of $\mathrm{CMI}$ as compared to the control group during both the treatment and post-treatment periods. In fact, during the whole experiment CMI $30 \mathrm{mg} / \mathrm{kg}$ group showed lower body weight gain $(2.26 \pm 0.5 \mathrm{~g} / \mathrm{d})$ when compared to the saline group $(4.09 \pm 0.7 \mathrm{~g} / \mathrm{d} ; p<0.001)$.

Pre-treatment, Treatment, and Post-treatment Diet Intakes Total Food Intake Changes in total daily energy intake for each block are shown in Fig. 2. ANOVA revealed a significant main effect of treatment $[F(3,24)=6.93, p=$ $0.001]$, block $[F(4,96)=18.1, p<0.0001]$ and treatment $\times$ block interaction $[F(12,96)=2.98, p=0.001]$. While $3 \mathrm{mg} / \mathrm{kg}$ 


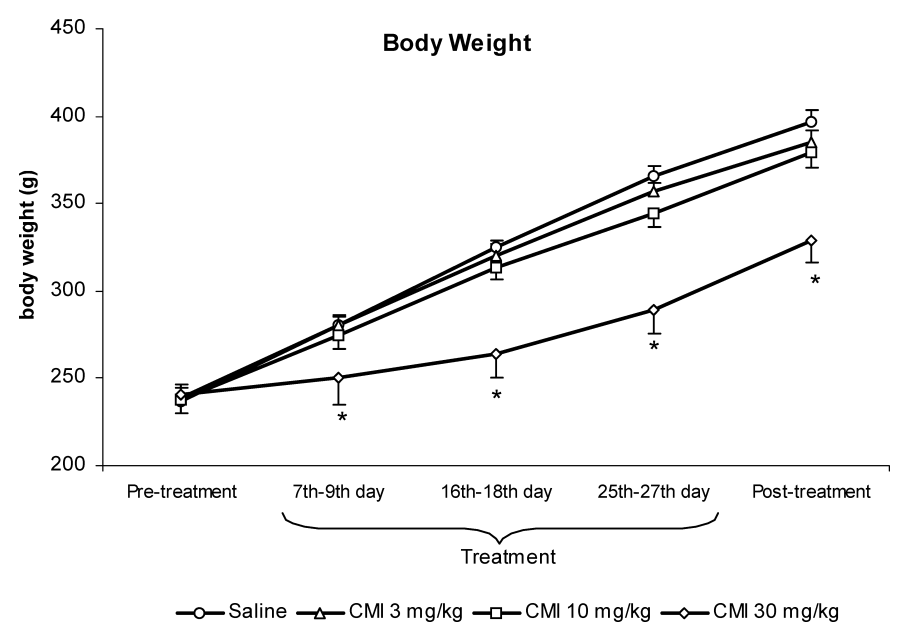

Fig. 1. Body Weight (g) in Rats Chronically Treated with CMI $(0,3,10$, $30 \mathrm{mg} / \mathrm{kg}$; i.p.) during $27 \mathrm{~d}$

Data are means $( \pm$ S.E.M.) of each $3 \mathrm{~d}$ period (see text) $* p<0.05$ versus control group.

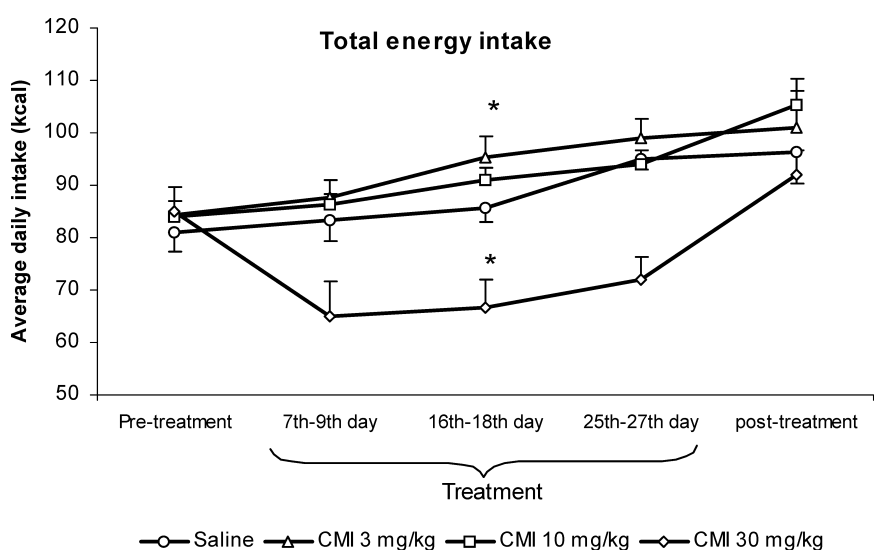

Fig. 2. Caloric Intakes (kcal) Variations in Rats Chronically Treated with CMI $(0,3,10,30 \mathrm{mg} / \mathrm{kg}$; i.p.) during $27 \mathrm{~d}$

Data are means ( \pm S.E.M.) of each $3 \mathrm{~d}$ block (see text for details). $* p<0.05$ versus control group.

of CMI increased the caloric intake on 16th-18th-day block, the highest dose $(30 \mathrm{mg} / \mathrm{kg})$ decreased food intake at the 7 th -9 th, 16th -18 th and 25th -27 th blocks of the treatment phase when compared to saline. The other blocks did not show statistical significant differences.

Intake of Macronutrient-Rich Diets Figure 3 illustrates the average energy intake from each macronutrientrich diet during the pre-treatment, treatment and post-treatment phases. For carbohydrate intake, ANOVA revealed a significant main effect of treatment $[F(3,24)=3.06, p<0.05]$, block $[F(4,96)=18.4, p<0.0001]$ and treatment $\times$ block interaction $[F(12,96)=2.17, p<0.02]$. Post hoc comparisons revealed that CMI $(30 \mathrm{mg} / \mathrm{kg})$ significantly decreased carbohydrate intake during the three blocks of drug treatment (7th-9th, 16th-18th, 25th-27th days) when compared to saline. Both fat $[F(3,24)=2.38, p=0.09]$ and protein $[F(3,24)=0.45, p=0.71]$ intakes were not significantly changed by CMI.

Effects of CMI on Carbohydrate Intake during the Early, Middle and Late Phases of the Dark Period Figure 4 shows carbohydrate intake during early $(19-23 \mathrm{~h})$,
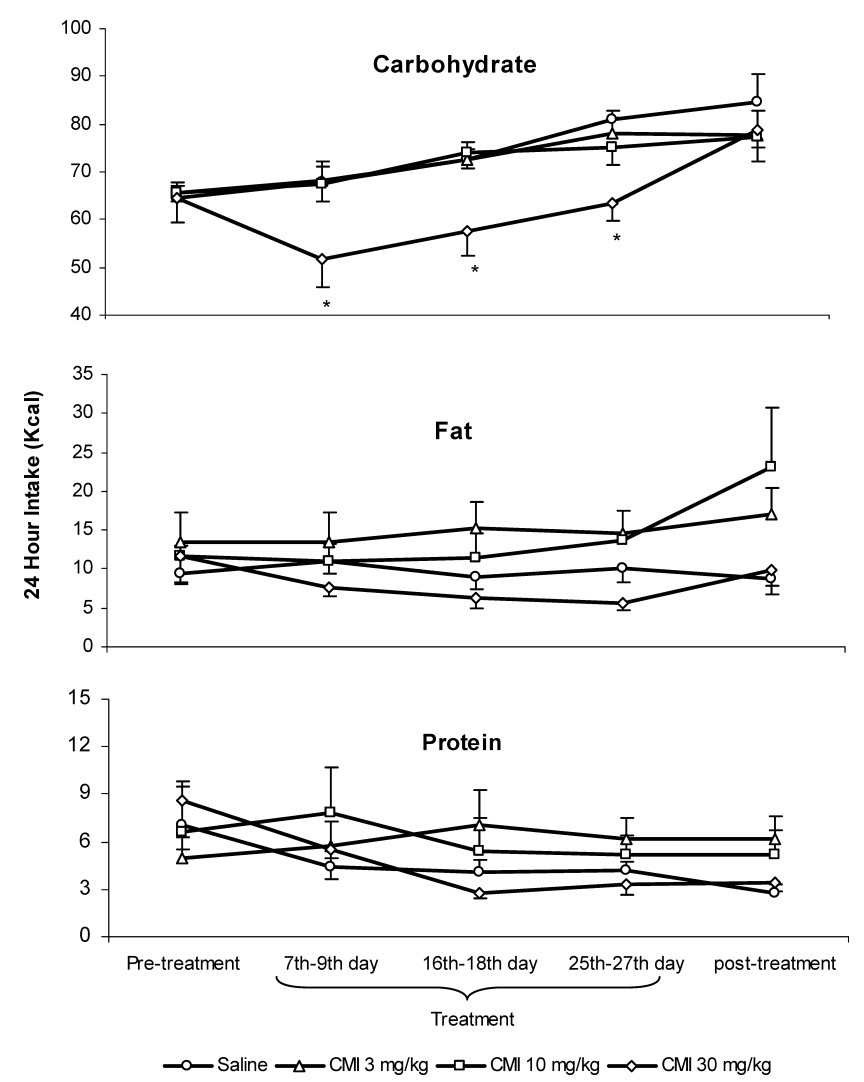

Fig. 3. Caloric Intakes (kcal) from Each Macronutrient (Carbohydrate, Fat and Protein) in Rats Chronically Treated with CMI (0, 3, 10, $30 \mathrm{mg} / \mathrm{kg}$, i.p.) during $27 \mathrm{~d}$

Data represent mean ( \pm S.E.M.) for each $3 \mathrm{~d}$ block (see text for details). $* p<0.05$ versus control group.
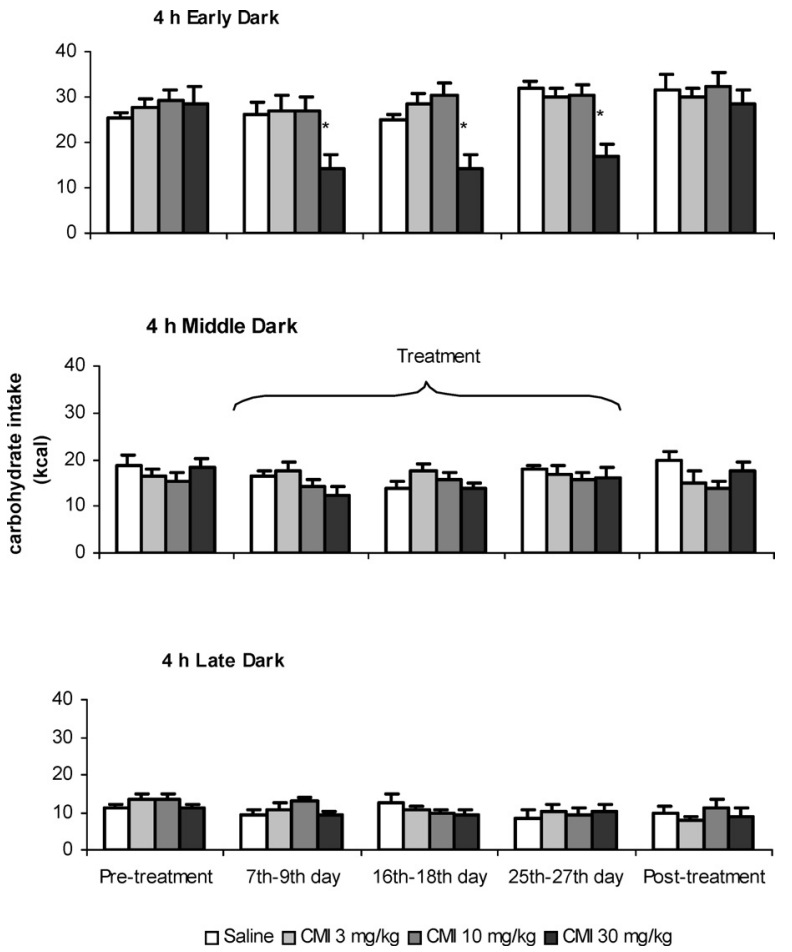

Fig. 4. Carbohydrate Intakes (kcal) during the 4-h Early, Middle, and Late Dark Phases in Rats Chronically Treated with Either CMI $(0,3,10$, $30 \mathrm{mg} / \mathrm{kg}$; i.p.) for $27 \mathrm{~d}$

Data represent mean $( \pm$ S.E.M.) for each $3 \mathrm{~d}$ period (see text for details). $* p<0.05$ versus control group. 
Table 2. Macronutrient Intake, Total kcal and Percent of Total Energy in Light and Dark Phases

\begin{tabular}{|c|c|c|c|c|c|c|c|c|c|c|}
\hline & \multicolumn{5}{|c|}{ Light phase } & \multicolumn{5}{|c|}{ Dark phase } \\
\hline & $\mathrm{C}$ & $\mathrm{P}$ & $\mathrm{F}$ & Total (kcal) & $\% \mathrm{E}$ & $\mathrm{C}$ & $P$ & $\mathrm{~F}$ & Total (kcal) & $\% \mathrm{E}$ \\
\hline Saline & $21.09 \pm 1.2$ & $0.97 \pm 0.4$ & $2.32 \pm 0.8$ & $24.38 \pm 1.3$ & 28.53 & $51.49 \pm 3.2$ & $3.04 \pm 0.4$ & $6.58 \pm 1.3$ & $61.11 \pm 2.5$ & 71.47 \\
\hline CMI 3 & $16.51 \pm 2.0$ & $1.31 \pm 0.5$ & $2.41 \pm 0.6$ & $20.24 \pm 2.5$ & 21.22 & $56.52 \pm 3.6$ & $5.70 \pm 1.7$ & $12.93 \pm 2.9$ & $75.16 \pm 4.1^{*}$ & 78.78 \\
\hline CMI 10 & $18.07 \pm 5.2$ & $0.74 \pm 0.1$ & $1.50 \pm 0.3$ & $20.31 \pm 4.9$ & 22.36 & $55.94 \pm 2.9$ & $4.68 \pm 2.0$ & $9.92 \pm 3.1$ & $70.55 \pm 4.8$ & 77.64 \\
\hline CMI 30 & $20.17 \pm 1.2$ & $0.52 \pm 0.1$ & $1.79 \pm 0.5$ & $22.49 \pm 1.4$ & 33.76 & $37.43 \pm 5^{*}$ & $2.25 \pm 0.3$ & $4.78 \pm 1.1$ & $44.46 \pm 5.4 *$ & 66.74 \\
\hline
\end{tabular}

Data are means $( \pm$ S.E.M. $)$ of $3 \mathrm{~d}$, between 16 th -18 th day of treatment. Rats chronically treated with CMI $(0,3,10,30 \mathrm{mg} / \mathrm{kg}$; i.p. $)$ during $18 \mathrm{~d}$. C $=$ carbohydrate, $\mathrm{P}=\mathrm{protein}$, $\mathrm{F}=$ fat. Total energy light or dark $(\% \mathrm{E})=\left[\right.$ carbohydrate + fat + protein $\left.\left(\mathrm{kcal} \mathrm{g}^{-1}\right)\right] \div\left[\right.$ total food intake $\left.\left(\mathrm{kcal} \mathrm{g}^{-1}\right)\right] \times 100 . * p<0.05$ versus saline .

middle $(23-03 \mathrm{~h})$ and late $(03-07 \mathrm{~h})$ dark phases. ANOVA revealed a significant effect of treatment $[F(3,24)=4.37$, $p<0.02]$, block $[F(4,96)=7.40, p<0.001]$ and treatment $\times$ block interaction $[F(12,96)=3.05, p<0.002]$ during the early phase. Contrast comparisons revealed that $30 \mathrm{mg} / \mathrm{kg}$ of CMI reduced carbohydrate intake during treatment period (from 7 th to 27 th day) when compared to saline. During post-treatment carbohydrate intake resumed to that recorded in the pre-treatment. Treatment with CMI did not significantly affect carbohydrate intake during both middle $[F(3,24)=0.75$, $p=0.52]$ and late $[F(3,24)=0.38, p=0.76]$ phases.

Food Intake in Dark and Light Phases during 16th18th Day Block Since CMI caused opposite effects on total food intake during the 16th-18th day block (see Fig. 2 ), a detailed analysis of the specific treatment effects was performed. Thus, the percentages of total energy intake $(\% \mathrm{E})$ and total kcal consumption either in the light or dark phases were analyzed. ANOVA revealed a significant main effect of treatment (Table 2) for caloric consumption $[F(3,24)=9.25$, $p=0.002]$ during the dark phase. Contrast comparisons revealed that $3 \mathrm{mg} / \mathrm{kg}$ and $30 \mathrm{mg} / \mathrm{kg}$ of CMI, respectively, increased and decreased total energy consumption (i.e. the caloric sum of the three macronutrients) when compared to the saline group. Such reduction of caloric consumption seemed to be due to the drug effect on carbohydrate intake, since CMI $30 \mathrm{mg} / \mathrm{kg}$ significantly decreased this diet intake when compared to the saline group (see Table 2).

\section{DISCUSSION}

This study demonstrated that chronic treatment with CMI significantly decreased body weight gain and energy intake. Reduction of total energy intake was markedly related to a decrease in the intake of carbohydrate-rich diet. An expected increase in food consumption followed by chronic treatment with CMI was not confirmed in the present study, since only the lower dose of this TCA increased total energy intake, an effect that was observed during a single block (16th-18th day) of drug treatment.

Considering food intake during pre-treatment period, the present results corroborate previous findings showing that rats consume more food during the dark phase than in the light period. ${ }^{30,31)}$ Food intake was significantly higher in the dark phase than in the light phase during pre-treatment $(65.9 \pm 2.2 \mathrm{kcal} v s$. $15.1 \pm 2.2 \mathrm{kcal}, p<0.001)$, which corresponds to $81.3 \%$ and $18.7 \%$ of ingested calories, respectively. In fact, carbohydrate diet was preferentially consumed when compared to protein and fat diets throughout the experiment (see Fig. 3). This result corroborates previous studies showing that rats choose a large amount of calories as carbohydrate-diet in self-selecting paradigms. ${ }^{31)}$ However, there are also conflicting data with reports showing that rats distributed their daily caloric intakes equally eating nutrients in a way that each one represents one third of daily calories. ${ }^{30)}$ Moreover, it has been shown that rats select macronutrients by consuming more fat and protein diets than carbohydrate diet. ${ }^{32)}$ Such discrepancies may be related to the fact that food choice varies with the type of macronutrients used in the diet, the number of available choices and the sensorial and hedonic aspects of the food. ${ }^{33-35)}$

Casein was used as the protein source in present experiment and in previous studies. ${ }^{36-38)}$ Although we have used it in a granular preparation, a form that has been suggested to be more readily acceptable by rats ${ }^{29)}$ our results showed a small amount of protein intake. It has been demonstrated ${ }^{31,39)}$ that protein intake is more tightly regulated than fat or carbohydrate intake. Moreover, under a dietary self-selection regimen rats are more likely to develop conditioned aversion to the protein source than the carbohydrate source. ${ }^{40)}$ Fat intake was also low when compared to previous studies. ${ }^{32,41)}$ It is important to note that protein and fat intake displayed by rats in this experiment was lower than that observed in humans. In human beings, protein intake is limited to $15-20 \%$ while lipids provide up to $40 \%$ and carbohydrate up to $50 \%$ of macronutrient intake. ${ }^{42,43)}$

When establishing the protocol of the dietary self-selection, we anticipated that CMI-induced neuroadaptations might affect food intake and increase the preference for carbohydrates, a mechanism that could be related to the increase in caloric intake, carbohydrate craving, and body weight gain in humans treated with CMI. However, in the present study, chronic administration of CMI at the highest dose $(30 \mathrm{mg} / \mathrm{kg})$ resulted in a consistent decrease of total energy intake, an effect likely related to a reduction of carbohydrate intake during the early dark phase (see Fig. 4). This short period effect of CMI could be related to its pharmacokinetics in rats. $\mathrm{Fu}-$ jita et $a l .{ }^{44)}$ demonstrated that CMI half-life is about $4 \mathrm{~h}$. Weigmann et al. ${ }^{45)}$ also investigated the pharmacokinetics of CMI and its active metabolite desmethylclomipramine in rats. They showed that maximal concentrations of CMI and desmethylclomipramine occurred at $2-3 \mathrm{~h}$ following oral administration. Serum and brain half-lives were similar in serum and brain with 7.8 and $6.2 \mathrm{~h}$ for CMI and 5.5 and $5.0 \mathrm{~h}$ for desmethylclomipramine. Thus, CMI might produce more consistent acute effects in procedures involving twice i.p. drug administration a day or by mixing it with food. Nevertheless, although other TCA (e.g. imipramine and desipramine) also present short intracerebral half-lives, ${ }^{46,47)}$ it 
must be emphasized that when given once or twice a day for $14 \mathrm{~d}$ they are present in the brain for the whole interval between injections at concentrations sufficient to inhibit noradrenaline and serotonin uptake. ${ }^{48)}$

In contrast, the lowest dose $(3 \mathrm{mg} / \mathrm{kg})$ induced a significant, but transient, increase in total caloric intake. This result was observed in the 16th to 18th day of CMI treatment, an effect that was neither macronutrient-specific nor followed by body weight gain (Table 2).

Although it has been shown that acute injections of CMI increase carbohydrate intake ${ }^{15)}$ most studies concerning longterm administration of TCA have shown either no changes or a reduction of food and carbohydrate intake. Indeed, a more detailed analysis showing the effects of desmethylimipramine on food intake has revealed that this TCA initially reduces food consumption, but losses its effects over a long-term treatment $(30 \mathrm{~d})$ with animals returning food intake towards pretreatment levels. ${ }^{16)}$ Nobrega and Coscina ${ }^{22)}$ showed that despite manipulations such as drug dosage, route and regime of administration, diet composition and palatability, animal gender and housing conditions, chronic treatments with TCA did not increase food intake or rates of weight gain in rats. The food intake reduction and weight loss observed in CMItreated animals may be related to the selectivity of this TCA in blocking serotonin reuptake. ${ }^{49)}$ In fact, selective serotonin reuptake inhibitors were thought to induce weight loss rather than weight gain in patients without psychiatric disorders. ${ }^{2}$ Thereafter, it is relevant to identify the mechanisms by which CMI decrease food intake and body weight. However, it must be emphasized that CMI effects on body weight and food consumption observed in the present study were obtained only with the highest dose $(30 \mathrm{mg} / \mathrm{kg})$. At $30 \mathrm{mg} / \mathrm{kg} / \mathrm{d}, \mathrm{CMI}$ may be toxic for rats. Thus, both reductions on food intake and body weight are likely related to the drug toxicity. The recovery in total energy intake observed after drug treatment period (see Fig. 2; group CMI-30 mg/kg) seems to corroborate this hypothesis.

In conclusion, the use of macronutrient self-selection protocol in this study provided results that corroborate previous findings demonstrating that chronic treatment with TCA does not increase food consumption and body weight gain in experimental animals. ${ }^{16,22)}$ It has been demonstrated that chronic treatment with tricyclic antidepressants elicit brain monoamine receptor adaptations. ${ }^{17-21)}$ However, present results suggest these possible neurochemical changes neither influence food consumption nor body weight gain. In addition, the present results do not support clinical findings, which have indicated that long-term treatment with TCA can induce body weight gain and carbohydrate craving in a significant proportion of patients. Further studies, particularly those resembling human regimen of macronutrient intake, should be designed to examine the mechanisms by which TCA like CMI affects macronutrient consumption. Moreover, besides affecting serotonergic and noradrenergic neurotransmissions CMI also binds to other receptors such as $\mathrm{H} 1$ and muscarinic receptors. Thus it is also relevant to investigate the mechanisms by which this TCA affects food consumption.

Acknowledgements This study was supported by FAPESP (Proc. 01/00189-9), PADC/FCF-Unesp. L. Calegari was recipient of FAPESP scholarship (and 02/06835-2) and R.L. Nunes-de-Souza received a CNPq research fellowship (302035/2003).

\section{REFERENCES}

1) Aronne L. J., Segal K. R., J. Clin. Psychiatry, 64, 22-29 (2003).

2) Zimmermann U., Kraus T., Himmerich H., Schuld A., Pollmächer T., J. Psychiatry Res., 37, 193-220 (2003).

3) Allison D. B., Mentore J. L., Heo M., Chandler L. P., Cappelleri J. C., Infante M. C., Weiden P. J., Am. J. Psychiatry, 156, 1686-1696 (1999).

4) Masand P. S., Expert. Opin. Pharmacother., 1, 377-389 (2000).

5) Fava M., J. Clin. Psychiatry, 61, 37-41 (2000).

6) Ruetsch O., Viala A., Bardou H., Martin P., Vacheron M. N., Encephale, 31, 507-516 (2005).

7) Thibault L., Booth D. A., Neurosci. Biobehav. Rev., 23, 457-528 (1999).

8) Mok E., Paquette M., Thibault L., Appetite, 34, 313-325 (2000).

9) Tempel D. L., Leibowitz S. F., Brain Res. Bull., 25, 821-825 (1990).

10) Currie P. J., Coscina D. V., Brain Res., 627, 153-158 (1993).

11) Ookuma K., Sakata T., Fujimoto K., Psychopharmacology (Berl), 101, 481-485 (1990).

12) Paykel E. S., Mueller P. S., De la Vergne P. M., Br. J. Psychiatry, 123, 501-507 (1973).

13) Kazes M., Danion J. M., Grange D., Pradignac A., Simon C., Burrus Mehl F., Schlienger J. L., Singer L., J. Affect. Disord., 30, 193-207 (1994).

14) Bouwer C. D., Harvey B. H., Int. Clin. Psychopharmacol., 11, 273278 (1996).

15) Leibowitz S. F., Brown O., Tretter J. R., Kirschgessner A., Pharmacol. Biochem. Behav., 23, 541-550 (1985)

16) Durcan M. J., McWilliam J. R., Campbell I. C., Neale M. C., Dunn G., Pharmacol. Biochem. Behav., 30, 299-302 (1988).

17) Duncan G. E., Paul I. A., Powell K. L., Fassberb J. B., Stumpf W. E., Breese G. R., J. Pharmacol. Exp. Ther, 248, 470 - 477 (1989).

18) Newman-Tancredi A., Verrièle L., Chaput C., Millan M. J., Brain Res. Bull., 41, 93-96 (1996).

19) Scavone C., Aizenstein M. L., DeLucia R., Planeta C. S., Eur. J. Pharmacol., 132, 263-267 (1986).

20) Scavone C., Aizenstein M. L., Planeta C. S., DeLucia R., Gen. Phar mac, 23, 397-401 (1992).

21) Schoups A. A., De Potter W. P., Biochem. Pharmacol., 37, 44514460 (1988).

22) Nobrega J. N., Coscina D. V., Pharmacol. Biochem. Behav., 27, 105112 (1987).

23) The Expert Consensus Guideline Series, J. Clin. Psychiatry, 58, $1-72$ (1997).

24) Lotufo-Neto F., Bernik M., Ramos R. T., Andrade L., Gorenstein C., Cordas T., Melo M., Gentil V., J. Psychopharmacol., 15, 13-17 (2001).

25) Gorenstein C., Gentil V., Melo M., Lotufo-Neto F., Lauriano V., J. Psychopharmacol., 12, 246-251 (1998).

26) Gentil V., Lotufo-Neto F., Andrade L., Cordás T., Bernik M., Ramos R., Maciel L., Miyakawa E., Gorenstein C., J. Psychopharmacol., 7, 316 -324 (1993).

27) Marcourakis T., Gorenstein C., Gentil V., J. Psychopharmacol., 7, 325-330 (1993)

28) Ramos R., Gentil V., Gorenstein C., J. Psychopharmacol., 7, 265-269 (1993).

29) Mok E., Thibault L., Physiol. Behav., 65, 893-899 (1999).

30) Tempel D. L., Shor-Posner G., Dwyer D., Leibowitz S. F., Am. J. Physiol., 256, 541-548 (1989).

31) Larue-Achagiotis C., Martin C., Verger P., Louis-Sylvestre J., Physiol. Behav., 51, 995-999 (1992).

32) Jean C., Fromentin G., Tome D., Larue-Achagiotis C., Physiol. Behav., 76, 65-73 (2002).

33) Kanarek R. B., Am. J. Clin. Nutr., 42, 940-950 (1985)

34) Thibault L., Mok E., Nagai K., Wong C. Y., Physiol. Behav., 68, $37-$ 45 (1999)

35) Wetzler S., Jean C., Tome D., Larue-Achagiotis C., Physiol. Behav, 79, 695-700 (2003)

36) Leathwood P. D., Ashley D. V., Appetite, 4, 97-112 (1983). 
37) McArthur R. A., Blundell J. E., Physiol. Behav., 38, 315-319 (1986).

38) Cambraia R. P., Vannucchi H., Almeida S. S., De-Oliveira L. M., $N u$ trition, 17, 455-461 (2001).

39) Ackroff K., Sclafani A., Physiol. Behav., 44, 181-187 (1988).

40) Bernstein I. L., Goehler L. E., Fenner D. P., Behav. Neurosci., 98, 1065-1072 (1984).

41) Minet-Ringuet J., Even P. C., Guesdon B., Tome D., de Beaurepaire R., Behav. Brain Res., 163, 204-211 (2005).

42) Grundy S. M., Annu. Rev. Nutr., 19, 325-341 (1999).

43) Volatier J. L., Verger P., Br. J. Nutr., 81 (Suppl. 2), S57—S59 (1999).

44) Fujita K., Kobayashi A., Suzuki S., Nakazawa K., Eur. J. Pharmacol., 204, 227-233 (1991).
45) Weigmann H., Härtter S., Bagli M., Hiemke C., Eur. Neuropsychopharmacol., 10, 401-405 (2000).

46) Ragusi C., Scherrmann J.-M., Harrison K., Smith D. S., Rips R., Boschi G., J. Neurochem., 70, 2099-2105 (1998).

47) Sato Y., Shibanoki S., Sugahara M., Ishikawa K., Br. J. Pharmacol., 112, 625-629 (1994)

48) Daniel W., Adamus A., Melzacka M., Szymura J., Vetulani J., Naunyn Schmiedebergs Ach. Pharmacol., 317, 209-213 (1981).

49) Feldman R. S., Meyer J. S., Quenzer L. F., "Principles of Neuropsychopharmacology," Sunderland, Sinauer Associates Inc., Massachussets, U.S.A., 1997. 